\title{
Status of Remote Sensing of Salinity by Aquarius
}

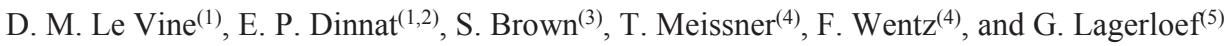 \\ (1) Goddard Space Flight Center, Greenbelt, MD 20771 \\ (2) CEESMO, Chapman University, Orange, CA 92866 \\ (3) Jet Propulsion Laboratory, Pasadena, CA 91109 \\ (4) Remote Sensing Systems, Santa Rosa, CA 95401 \\ (5) Earth and Space Research, Seattle, WA 98121
}

\begin{abstract}
Aquarius is an L-band instrument designed to measure sea surface salinity from space. The instrument was launched in 2011 and data acquisition ended in June 2015 when control of the spacecraft was lost. Aquarius produced global maps of salinity with accuracy of 0.2 psu and special resolution of $150 \mathrm{~km}$ as well as other products such as global maps of RFI and soil moisture. The mission will formally end December 2017.
\end{abstract}

\section{Background}

Aquarius is an active/passive combination instrument operating at L-band $(1.413 \mathrm{GHz}$ for the radiometer and $1.26 \mathrm{GHz}$ for the scatterometer) and designed for monitoring sea surface salinity from space [5]. The instrument was launched in July 2011 as part of the Aquarius/SAC-D observatory, a partnership between NASA and the Argentine space agency, CONAE. Aquarius functioned as designed until a power failure in June 2015 caused loss of control of the spacecraft and the end of the mission. During its nearly 4 years of operation, Aquarius provided global maps of sea surface salinity with an accuracy in the open ocean (global RMS monthly) of 0.2 practical salinity units (psu) with a spatial resolution of about $150 \mathrm{~km} \mathrm{[3,9].}$

Among the special features of Aquarius were:

- The presence of a radar operating at a frequency close to that of the radiometer and with a similar footprint [5]. The radar was designed to provide an instantaneous correction for surface roughness (waves) which is perhaps the largest source of error in the retrieval of salinity $[1,6]$.

- Rapid sampling (one sample each $10 \mathrm{~ms}$ ) to improve detection and mitigation of radio frequency interference (RFI). The Nyquist sampling time was about 7 seconds. The individual samples could be tested for RFI and, because of the oversampling, many could be discarded without severely degrading the effective radiometric resolution (NEDT) of the instrument [8].

- Polarimetric processing. The Aquarius radiometer measured vertical and horizontally polarized signal and also the third Stokes parameter (the correlation between the two). The third Stokes parameter was used to measure Faraday rotation in-situ and make a real-time correction [7].

- Careful thermal control: A combination of active and passive thermal control kept the radiometer front end within $0.1{ }^{\circ} \mathrm{C}$ per orbit $[5,11]$.

Aquarius was designed to map the globe in 7 days and produced weekly and monthly maps. Figure 1 is an example. This is a global map of sea surface salinity for the week of June 23, 2012 (top) and six months later, January 16, 2013 (bottom). These maps illustrate some of the dynamic features of the salinity field that the perspective from space helped to illuminate. In particular, notice the change between the two seasons in the relatively fresh water in the central Pacific Ocean
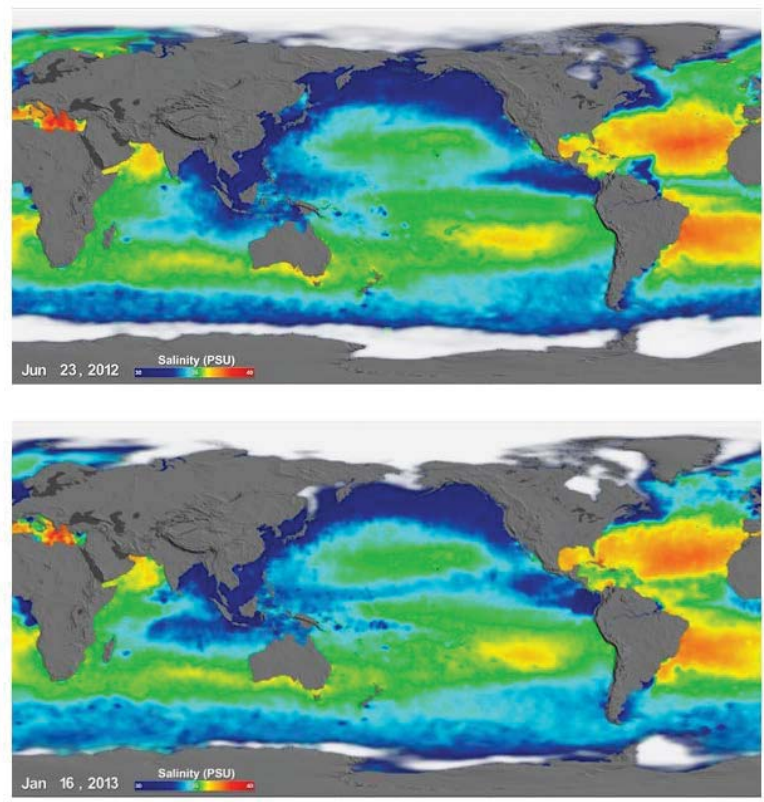

Fig. 1: Global maps of salinity for the weeks of January 23, 2012 and January 16, 2013. 
associated with the ITCZ. The ITCZ is clearly evident in January, including a southern branch, but less strong in June. Also notice the freshwater outflow from the Amazon River (northeast coast of South America) which is strong and evident in June of 2012, but much less evident the following January. Other areas showing seasonal changes are the Indian Ocean which responds to river runoff associated with the monsoon season and fresh water off the western coast of South and Central America. Aquarius data is available at the NASA physical oceanography data archive: https://podaac.jpl.nasa.gov/aquarius.

In addition to the salinity maps, Aquarius provided new information about the global distribution of RFI at Lband, global maps of soil moisture over land, demonstrated the technology for measuring Faraday rotation, provided information about sea ice and insight into the synergistic use of active and passive measurements over land. Examples can be found at: https://aquarius.umaine.edu/cgi/data.htm. Figure 2 is an example of RFI observed by the radiometer. The radiometer operates in a band centered at $1.413 \mathrm{GHz}$ protected from manmade emission. The map shows percentage of data corrupted by RFI. Red areas are regions where RFI severely impacts the retrieval of science products. This is a much worse problem for operations over land (e.g. retrieval of soil moisture) but also impacts retrieval of SSS. A halo of RFI is clearly evident in this map in the North Atlantic and with better resolution it can be also be seen in the Pacific Ocean on the other side of North America. This is a consequence of sources of RFI on land strong enough to corrupt data from distant measurements [8]. Figure 3 is an example of a global map of soil moisture produced from Aquarius data. Data can be found at: https://nsidc.org/data/aquarius. The four panels show the global distribution of soil moisture for the four seasons. Frozen ground and dense vegetation canopy, areas where

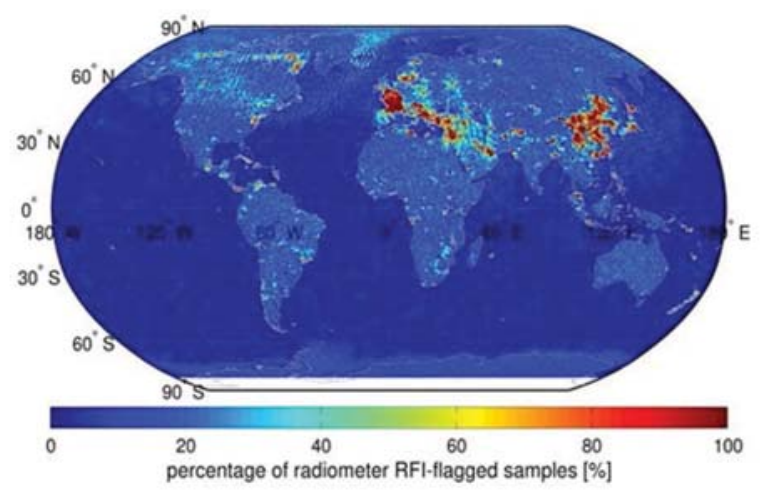

Fig 2: Percentage of Aquarius radiometer samples identified as RFI for the year, 2012. The percentage at each point is the average of both polarizations.
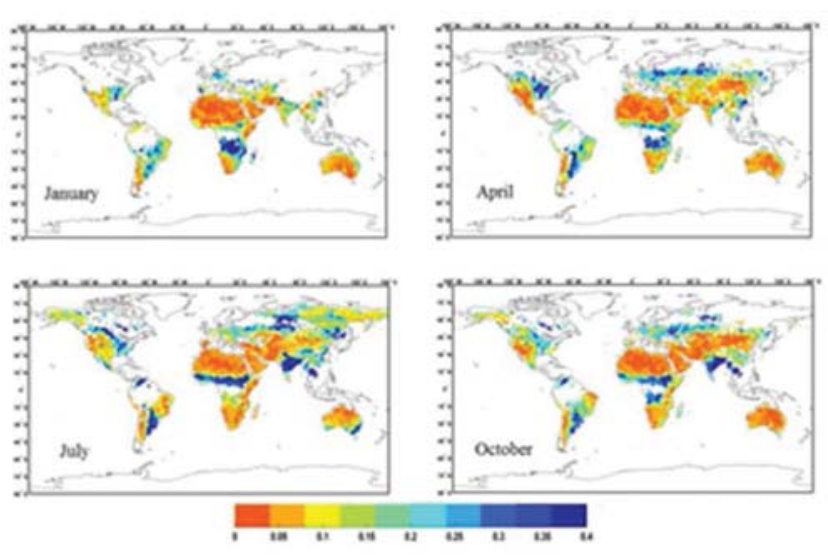

Fig 3: Monthly maps of soil moisture (volumetric) for the year 2012 derived from Aquarius measurements of brightness temperature.

soil moisture is not retrieved, appear white in these maps. For example, the melting associate with Spring in the Northern Hemisphere is clearly evident in the "April" map as is the significant increase in soil moisture in India associated with the monsoon (October).

\section{Status}

The Aquarius mission will formally end December 31, 2017. Operations have been formally closed and science activities are focused on release of the final salinity product, Version 5.0, scheduled for the Fall of 2017. Aquarius functioned well from turn-on in August, 2011 and a first image was reported in September. Steady improvements in the quality of the salinity product have been made over the course of the mission. Among the issues addressed along the way are [9]:

1. Radiometer drift: This is a drift in the radiometer gain most apparent in the early months of the mission (about $1 \mathrm{~K} / \mathrm{yr}$ ). The drift appears to be associated with a transient phenomenon associated with deployment in space (e.g. outgassing) and decayed to nearly zero in the last years of the mission. The drift is removed in calibration by fitting an exponential to the full history of data.

2. Wiggles: The residual after removal of the exponential drift has the appearance of zero mean "wiggles". These were traced to an issue with radiometer backend (voltage to frequency converter) and a correction was implemented. The "wiggles" were reduced but did not disappear. Currently, as of the time of this manuscript, the residual has a pronounced seasonal cycle which correlates well with the Sun beta-angle and temperature variations in the radiometer front-end. Although the correlation is strong, a cause-and-effect has not been established.

3. Ascending/descending difference: Although the geometry and ancillary parameters are different when the satellite passes over the same piece of ocean on ascending and descending passes, one would expect the retrieved 
salinity to be the same. Differences exist. They correlate well with the correction for the L-band signal from the Galaxy reflected from the ocean surface. An improvement in this correction developed using SMAP observations of the Galactic signal will be implemented in Version 5.0. There is still a residual which is removed empirically (called "symmeterization" in Aquarius documentation).

4. Sea surface temperature (SST) dependence: The error in the retrieved salinity when compared to in situ observations (e.g. from Argo floats) shows a strong correlation with SST. This is probably due to a combination of things. For example, an adjustment to the temperature dependence in the oxygen absorption term in the model for the atmospheric had an impact. Also, it is known that the model used for the dielectric constant for sea water is important. For example, the Klein-Swift model [2] and Meissner-Wentz model [10] yield different SST bias. An empirical correction is currently being made by adjusting the temperature dependence of the Meissner-Wentz model to remove this bias.

5. Regional bias: Even after best effort, regions exist with larger errors than the average when compared to in situ measurements of salinity. Some (e.g. descending passes in the North-East Atlantic off the coast of Europe) appear in regions of strong RFI and may be due to low level RFI missed in the Aquarius RFI detection-mitigation algorithm. Others, such as at extreme southern latitude, may be due to the presence of rough seas and decreased sensitivity in cold water. These regions are removed during calibration and in generating the Level 3 product (monthly gridded maps). This remains an area in need of continued research.

\section{Future}

The Aquarius mission will end December 31, 2017 and Version 5.0 of the salinity retrieval will represent the best effort possible at this time. It is a good product meeting the mission requirements of 0.2 psu RMS globally on a monthly basis and spatial resolution of $150 \mathrm{~km}$. But there is more that can be done. The following are things that are underway but will not be completed in time to be included in the final version (V5.0):

- Improvements in the model for emission from land and associated improvements in the tables for contamination from land and sea ice;

- Improvements in the detection of low level of RFI;

- Evaluation of ancillary surface salinity fields other than HYCOM to use a reference salinity;

- Use of rain rates from CMORPH to correct for effects of liquid water on attenuation in the atmosphere.

- Completion of a data base of matched satellite and surface measurements (e.g. for evaluating the retrieved SSS).

- Revisiting the calibration of the measurement of the third Stokes parameter.
The data produced by Aquarius remains an outstanding resource, not only as source of data on the global dynamics of sea surface salinity, but also as a resource to learn how to retrieve seas surface salinity. The quality of the measurement, including both radar and radiometer, allows one to pursue research to push the limits on the potential accuracy for retrieving salinity. For example, the residual dependence on sea surface temperature in the retrieved salinity is clearly dependent on the model function used for the dielectric constant for sea water. The Aquarius data is a resource to help determine the best model function. In particular, the data can be used to assess the model function being developed by the team at the George Washington University [4] based on direct measurements at $1.413 \mathrm{GHz}$. Another example is the potential for new information regarding the roughness correction, which, even with the presence of the scatterometer, remains an issue especially at high winds. It is possible that some of the residual error at high latitudes is due to an incomplete understanding of the relationship between radar backscatter and "excess emissivity" contributed by surface roughness.

\section{Conclusion}

Aquarius has been a highly successful mission to demonstrate the feasibility of remote sensing sea surface salinity from space and providing new insight into the dynamics of the salinity field. Among its achievements is a look at the seasonal variation of the salinity field. SMAP and SMOS remain in space and the first salinity maps from SMAP have emerged. But, Aquarius was unique because it was dedicated to measuring salinity and design compromises were made with this goal in mind. It met its objectives and we believe it has functioned well enough to warrant a follow on mission in the future.

\section{References}

1. J. Font, G.S.E. Lagerloef, D.M. Le Vine, A. Camps, QZ. Zanife, "The Determination of Surface Salinity with the European SMOS Space Mission”, IEEE Trans. Geosci. Remote Sens., Vol. 42, no. 10, pp. 2196-205, October 2004; DOI 10.1109/TGRS.2004.834649.

2. Klein L. and C. Swift, "An improved model for the dielectric constant of seawater at microwave frequencies", IEEE TAP 25, pp 104-111, 1977.

3. G.S.E. Lagerloef, F. R. Colomb, D. M. Le Vine, F. Wentz, S. Yueh, C. Ruf, J. Lilly, J. Gunn, Y. Chao, A. deCharon, G. Feldman and C. Swift, "The Aquarius/SACD Mission: Designed to meet the salinity remote-sensing challenge," Oceanography, vol. 21, no. 1, pp. 68-81, March 2008.

4. Lang, R., Y. Zhou, C. Utku, and D. Le Vine, "Accurate measurements of the dielectric constant of 
seawater at L band", Radio Sci., 51, pp 2-24, doi:10.1002/ 2015RS005776, 2016.

5. Le Vine D. M., G. Lagerloef, F. R. Colomb, S. H. Yueh and F. A. Pellerano, "Aquarius: An instrument to monitor sea surface salinity from space", IEEE Trans. Geosci. Remote Sens. Vol 45 No. 7, pp 2040-2050, $207 .$.

6. D. M. Le Vine, G. S. E. Lagerloef and S. E. Torrusio, "Aquarius and remote sensing of sea surface salinity from space", Proceedings of the IEEE, vol. 98, no.5, pp.688703, May 2010.

7. D. M. Le Vine, S. Abraham, C. Utku and E.P. Dinnat, "Aquarius Third Stokes Parameter Measurements: Initial Results", IEEE Geoscience and Remote Sensing Letters, Vol. 10, no. 3, pp. 520-524, May, 2013.

8. D. M. Le Vine, P. de Matthaeis, C. S. Ruf and D. D. Chen, "Aquarius RFI detection and mitigation algorithm: assessment and examples," Geoscience and Remote Sensing, IEEE Transactions on, vol. 52, no. 8, pp. 4574,4584, August 2014.

9. D. M. Le Vine, E.P. Dinnat, T. Meissner, S.H. Yueh, F.J. Wentz, S.E. Torrusio and G. Lagerloef, "Status of Aquarius/SAC-D and Aquarius Salinity Retrieval", IEEE Journal of Select Topics in Applied Earth Observation and Remote Sensing, vol. 8, no. 12, pp. 5401-5415, December, 2015.

10. Meissner T. and F. Wentz, "The complex dielectric constant of pure and sea water from microwave satellite observations", IEEE Trans. Geosci. Remote Sens. Vol 42, No. 9, pp 1836-1849, 2004.

11. Piepmeier, J. R., L. Hong, and F. A. Pellerano, "Aquarius L-Band Microwave Radiometer: 3 Years of Radiometric Performance and Systematic Effects", IEEE J. Sel. Top. Appl. Earth Obs. Remote Sens., vol. 8, no. 12, 5416-5423, 2015. 